\title{
Índice general
}

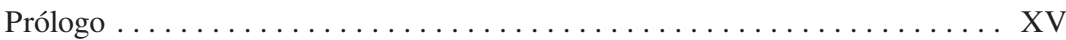

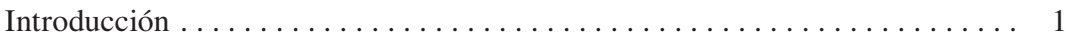

Primera Parte:

Teoría, metodología y análisis cuantitativo $\ldots \ldots \ldots \ldots \ldots \ldots \ldots \ldots$

1. El plan de investigación $\ldots \ldots \ldots \ldots \ldots \ldots \ldots \ldots \ldots \ldots \ldots \ldots \ldots$

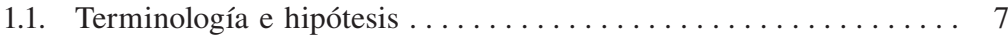

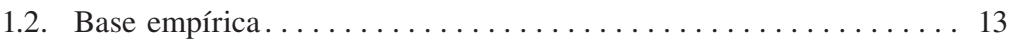

1.3. Reflexiones metodológicas................... 16

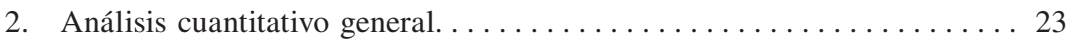

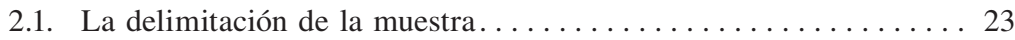

2.2. Panorama general de los signos discursivos............. 25

2.3. Los atributos enunciativos con forma de adjetivo . . . . . . . 27

2.4. Los adverbios atributivos enunciativos en -mente .......... 28

2.5. Los adverbios atributivos enunciativos con forma simple... . . . 29

2.6. Los adverbios no atributivos con forma propia . . . . . . . . . . . 29

2.7. Los adverbios enunciativos sintagmáticos ............ 30

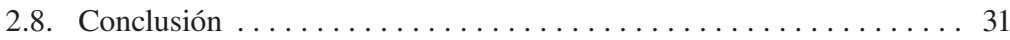

Segunda Parte:

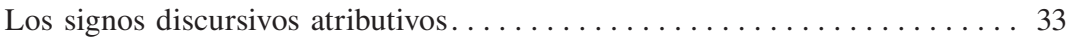

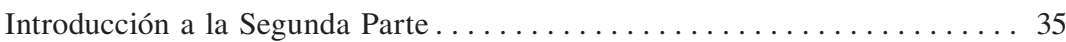

3. Claro, bueno, bien, igual, total, cierto - relaciones

subyacentes, técnicas discursivas y polifuncionalidad ......... 37

3.1. Claro y la construcción cooperativa ofensiva de la comunicación . . . . . . . . . . . . . . . . . . . . . . . 37

3.2. Bueno y la construcción cooperativa defensiva de la comunicación ........................ 45 


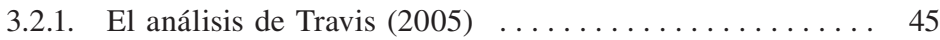

3.2.2. Las funciones intradiscursivas de bueno .......... 47

3.2.3. La naturaleza bicefálica del marcador del discurso bueno . . 54

3.2.4. Las funciones interdiscursivas de inicio de turno y recogida de turno. ................... 62

3.2.5. Tipo de comunicación, papel comunicativo y poder

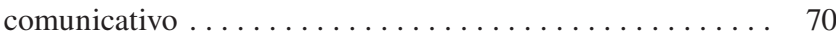

3.3. Bien - entre aceptación y retorno al rigor argumentativo. . . . . 74

3.4. Igual - polisemia y polifuncionalidad ............. 79

3.4.1. Los tres significados de igual............... 80

3.4.2. De la sincronía actual a la conjetura diacrónica ....... 83

3.4.3. El continuo funcional de igual en la dinámica

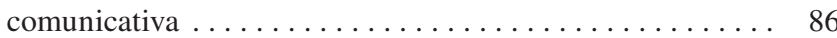

3.4.4. Igual - un marcador discursivo pasado por alto . . . . . . 89

3.5. Total - marcador coloquial de recapitulación somera y

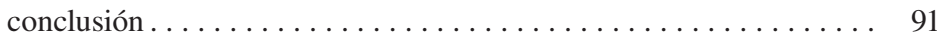

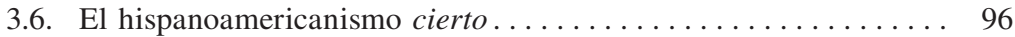

3.7. Las técnicas de discursivización y subjetivización . . . . . . . 100

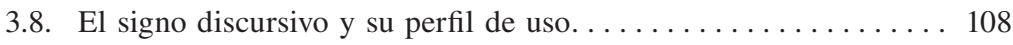

3.8.1. La perspectiva lexicológica ante el determinismo

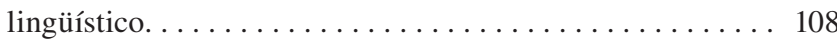

3.8.2. De la lexicología a la lexicografía ............. 111

3.8.3. Perfil de uso de claro .................... 113

3.8.4. Perfil de uso de bueno . . . . . . . . . . . . . . . . . . . 116

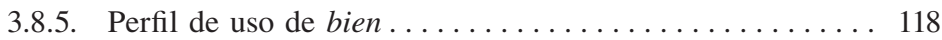

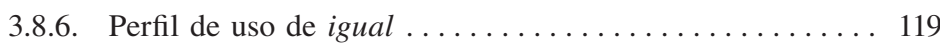

3.8.7. Perfil de uso de total. . . . . . . . . . . . . . . . . . . . 121

3.8.8. Perfil de uso de cierto.................... 122

3.9. Conclusión ......................... 123

4. Incluso, solo, justo, cierto, puro, mero, mismo, único, propio

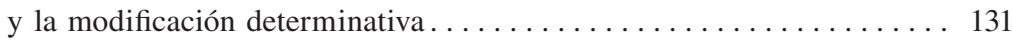

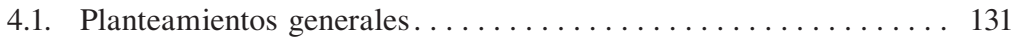

4.2. Incluso - marcador de enfoque y conector discursivo . . . . . 135

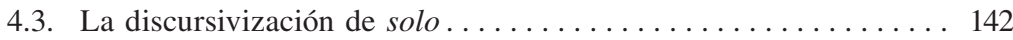

4.4. Justo y el enfoque enfático de la referencia. . . . . . . . . . . . . . 147

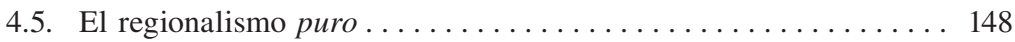

4.6. El regionalismo mero. . . . . . . . . . . . . . . . . . . . 149

4.7. Cierto y la modificación determinativa alusiva . . . . . . . . 150

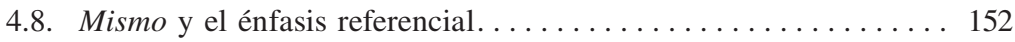

4.9. Propio y el contraste entre propiedad y comportamiento . . . . . . 154

4.10. Único y el énfasis referencial . . . . . . . . . . . . . . . . . . . 154

4.11. Preciso y el enfoque enfático de la referencia............ 155

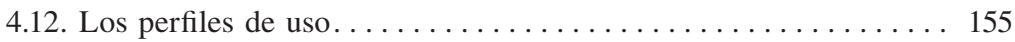


4.12.1. Perfil de uso de incluso. ................. 155

4.12.2. Perfil de uso de solo .................... 156

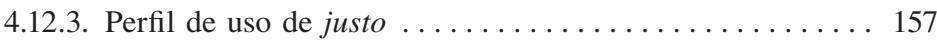

4.12.4. Perfil de uso de puro, mero, cierto, mismo, propio, único y preciso ....................... 158

4.13. Conclusión ........................... 158

5. Exacto, horrible, mejor y la cuestión de la productividad

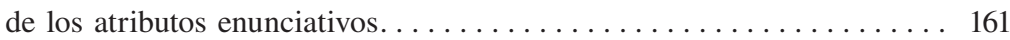

5.1. Exacto y otros atributos enunciativos afirmativos .......... 161

5.1.1. Exacto y el saber o poder comunicativos ........... 161

5.1.2. Lógico, obvio, perfecto, el estrato social y el habla

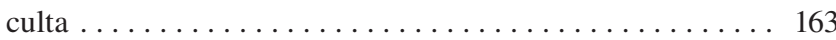

5.2. Fijo - un atributo afirmativo en boga............... 164

5.2.1. Fijo y el camino de la polifuncionalidad. . . . . . . . . 164

5.2.2. Fijo y la función de intensificación ............ 166

5.2.3. Fijo - un marcador discursivo en boga divulgado

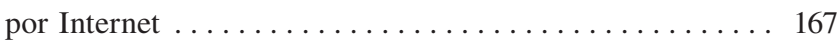

5.3. El paradigma productivo y sustitutivo de los atributos enunciativos afirmativos. . . . . . . . . . . . . . . . . . 167

5.4. ¿ ....y dónde están los atributos enunciativos de negación? . . . . . 169

5.5. Horrible y los atributos enunciativos valorativos. . . . . . . . . . . 169

5.6. Los atributos enunciativos valorativos, los adjetivos destacados y las construcciones absolutas . . . . . . . . . . . . 173

5.7. Mejor y la función deóntica $\ldots \ldots \ldots \ldots \ldots \ldots \ldots \ldots \ldots \ldots \ldots$

5.8. Los atributos enunciativos cultos inclusive, exclusive, máxime, independiente . . . . . . . . . . . . . . . . . . . . . 178

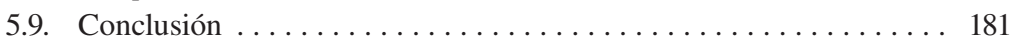

Conclusión de la Segunda Parte . . . . . . . . . . . . . . . . . . 183

Tercera Parte:

Dos signos discursivos no atributivos: o sea y entonces............ 191

Introducción a la Tercera Parte . . . . . . . . . . . . . . . . . 193

6. O sea - conector de coherencia argumentativa inferencial

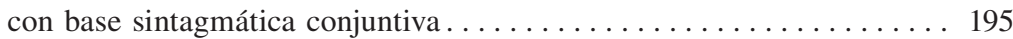

6.1. Las funciones de $o$ sea según Travis (2005) . . . . . . . . . 195

6.2. Las funciones discursivas de $o$ sea en el Corpus Kluge........ 196

6.3. Significado conceptual y funciones de $o$ sea . . . . . . . . . . . 199

6.4. Motivación y función discursiva . . . . . . . . . . . . . 202

6.5. Polifuncionalidad y homonimia sintáctica . . . . . . . . . 204 
6.6. La supuesta relación de equivalencia expresada con $o$ sea . . . . 207

6.7. Las funciones fáticas y el uso como muletilla . . . . . . . . 208

6.8. Acerca de la relevancia comunicativa de las muletillas . . . . . 212

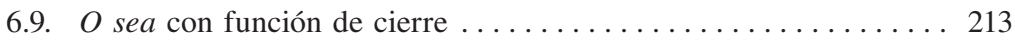

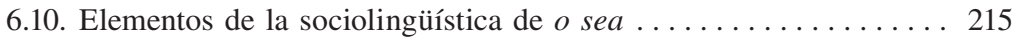

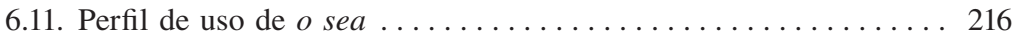

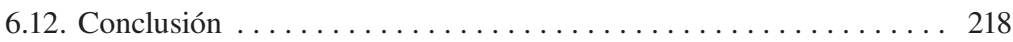

7. Entonces- conector secuencial-consecuencial con base ......... 221

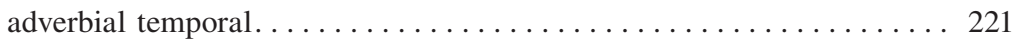

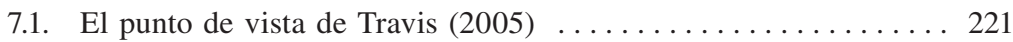

7.2. La hipótesis de una ruptura homonímica diacrónica........ 223

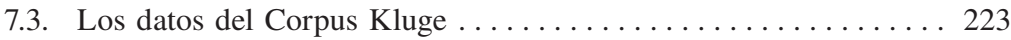

7.3.1. Significado temporal y secuencia narrativa . . . . . . . . 224

7.3.2. Secuencia temporal y consecuencia lógica . . . . . . . 227

7.3.3. Secuencia temporal, secuencia lógica y secuencia narrativa: una red motivada . . . . . . . . . . . . . . . 228

7.4. La hipótesis de una ruptura homonímica como artefacto

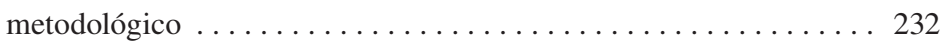

7.5. La metáfora secuencia-consecuencia y la semántica de entonces ........................... 234

7.6. De la motivación semántica a la conjetura diacrónica. . . . . . . 238

7.7. La discursivización de entonces y el tiempo presente. . . . . . . . 240

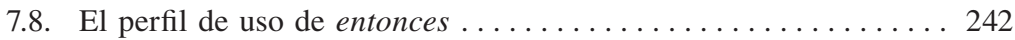

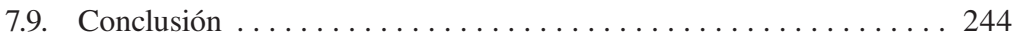

Conclusión de la Tercera Parte . . . . . . . . . . . . . . . . . . . 247

Cuarta Parte:

Elementos de variación lingüística . . . . . . . . . . . . . . . 249

8. Los adverbios enunciativos en -mente y la variación diamésica......251

8.1. Los adverbios enunciativos en -mente entre escritura y

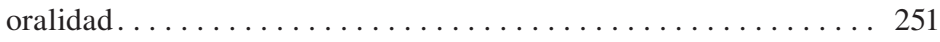

8.1.1. La variación diamésica como problema metodológico . . . 251

8.1.2. La frecuencia de los adverbios en -mente orales y

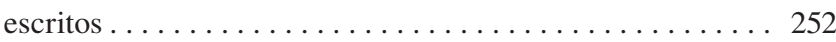

8.1.3. Formalidad e informalidad en el uso de los adverbios

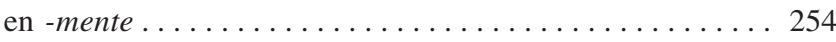

8.1.4. La tradición escrita panrománica .............. 256

8.1.5. Conclusiones ....................... 258

8.2. La delimitación de los adverbios enunciativos en -mente ...... 262

8.3. Origen diacrónico y frecuencia sincrónica.............. 264 
8.4 Los atributos enunciativos en -mente del Corpus Kluge . . . . . . 264

8.4.1 Solamente - un equivalente de solo con frecuencia excepcional ............................. 264

8.4.2. Realmente - intensificador enunciativo epistémico..... . 269

8.4.3. Simplemente - mitigador enunciativo........... 271

8.4.4. Generalmente - circunstancia enunciativa delimitativa . . 272

8.4.5. Definitivamente, efectivamente, precisamente, probablemente, seguramente ............... 272

8.5. Discursivización, intensificación / mitigación y cuantificación. . . 274

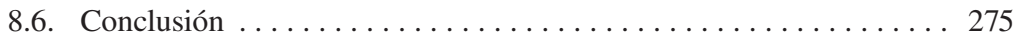

9. Elementos de variación lingüística sincrónica y diacrónica ....... 279

9.1. La competencia diasistemática de los atributos . . . . . . . . . . 279

9.2. Convergencias y divergencias diasistemáticas en la función

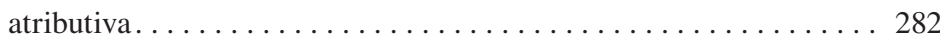

9.3. La variación idiolectal . . . . . . . . . . . . . . . . 284

9.4. Los atributos enunciativos en la expresión oral y la expresión escrita . . . . . . . . . . . . . . . . . . . . . . . . 290

9.5. El caso de los atributos con función de respuesta afirmativa . . . 296

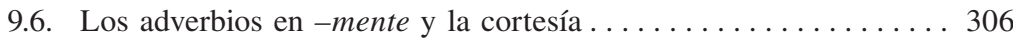

9.7. Hacia una diacronía de la variación diafásica . . . . . . . . . . 310

9.8. El caso de los modificadores determinativos . . . . . . . . . 315

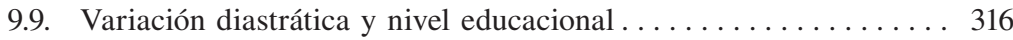

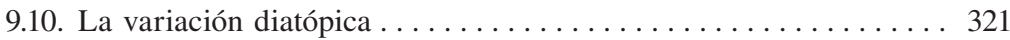

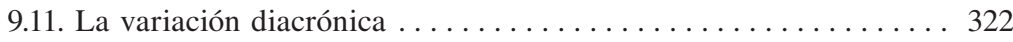

9.12. Conclusión ............................. 324

Conclusión de la Cuarta Parte.......................... 325

Quinta Parte:

Lexicalización y gramaticalización en los atributos enunciativos. . . . . . . 329

10. Atributos enunciativos y construcciones copulativas ¿una relación genética? ....................... 331

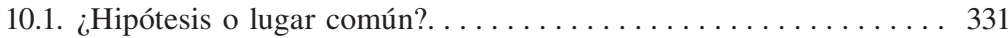

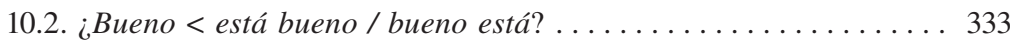

10.3. Bueno y bien ............................... 337

10.4. ¿Claro < está claro / claro está? . . . . . . . . . . . . . . . 339

10.5. Mejor, total e igual . . .................... 345

10.6. Resultado del análisis sincrónico-funcional . . . . . . . . . . 347

10.7. Los atributos enunciativos en la mímesis literaria del habla oral . . . . . . . . . . . . . . . . . . . . . . . . . . 349

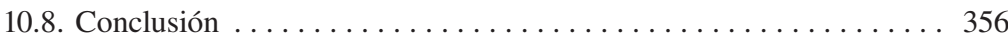


11. Los marcadores del discurso con base atributiva $-\ldots \ldots \ldots \ldots . \ldots 359$

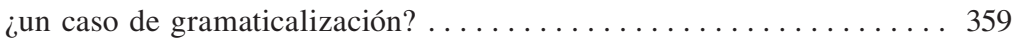

11.1. Gramaticalización: discursivización, pragmatización y oracionalización . . . . . . . . . . . . . . . . . . . . . . 359

11.2. Diacronía y sincronía en la gramaticalización de los

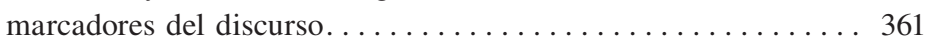

11.3. El nivel cero de la gramaticalización (gramaticalización $\left.n_{0}\right) \ldots \ldots 362$ 11.3.1. Los tipos de gramaticalización $n_{0} \ldots \ldots \ldots \ldots \ldots \ldots \ldots 365$ 11.3.2. Las propiedades lineales, graduales y variacionales de la gramaticalización $\mathrm{n}_{0} \ldots \ldots \ldots$. . . . . . . . . 369

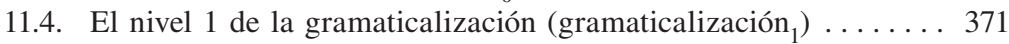

11.5. El nivel 2 de la gramaticalización $\left(\right.$ gramaticalización $_{2}$ ) . . . 374

11.6. Los marcadores discursivos atributivos invariables - ¿un caso de gramaticalización 〈local〉 por adverbialización o neutralización?......................... 383

11.7. La gramaticalización de total que.................. 394

11.8. O sea - ¿un caso de gramaticalización oral por ósmosis

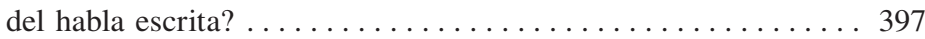

11.9. Uso y abuso de los índices de gramaticalización. . . . . . . . . 399

11.10. Conclusión. . . . . . . . . . . . . . . . . . . . . . . . . 404

Conclusión general. ........................... 407

Bibliografía y abreviaturas. . . . . . . . . . . . . . . 413 